\title{
Seepage Calculation and Analysis on the Eastern Slope of Yanshan Iron Ore
}

\author{
Yunyun Fan ${ }^{1, a}$, Nan Wang ${ }^{1, b}$ and Andong Sun ${ }^{1, c}$ \\ ${ }^{1}$ Key Laboratory of Ministry of Education on Safe Mining of Deep Metal Mines, Northeastern \\ University, Shenyang, 110004, China \\ ayunyunfan@126.com, b642677782@qq.com, c2214710743@qq.com
}

\begin{abstract}
Keywords: Yanshan iron ore; seepage calculation; anti-seepage project
Abstract. Yanshan iron ore open pit, located next to a river channel where quaternary epipedon large and thick covered on bedrock including seepage passage of highly permeable sandy gravel. As seepage engineering measures are necessary to ensure the production safety, the typical eastern slope section of nearby river channel was selected in this paper to make a seepage calculation and an analysis on the characteristics of seepage field and the control effect of anti-seepage measure on seepage field. The effective seepage control measure standards for engineering construction were also obtained through the calculation. The calculation results can provide reference to anti-seepage projects.
\end{abstract}

\section{The Engineering Situation}

Yanshan iron ore is located $3 \mathrm{~km}$ south of Luan County, Hebei, $8 \mathrm{~km}$ to the Luan County railway station in the north, and $4 \mathrm{~km}$ to the Lingjiaoshan railway station in the west. The mining method is surface mining with the stope divided by horizontal steps, and the mining began from top to bottom and layer by layer.

According to survey data, the quaternary epipedon of eastern slope of Yanshan iron ore is large and thick, and the inside fault structure is well developed. The quaternary stratigraphy, from top to bottom, is respectively miscellaneous fill soil, silty clay, silty sand, gravel and bedrock. The "Xin River" nearby the eastern stope which provides water supply as a constant-head, pours plenty of water into the stope through alluvial-diluvial sand and sandy gravel layer with extremely strong permeability and water abundance. There is a certain amount of ore in the bedrock superficially buried under the eastern slope epipedon. With the increasing mining depth of eastern slope, the upper quaternary soil and rock was stripped, the hydraulic gradient of both sides of the eastern slope will further increase, and the amount of water penetrating into the stope will also continuously increase. Although pump drain and other means have been used to reduce the water seepage inside, the instability of $50 \mathrm{~cm}$-thick topsoil slope will probably occur when the rainy season arrives without timely engineering treatment to the seepage passage of permeable and water-rich fine sand layer and gravel bed, and thus have a serious impact on mine production. Several studies have shown that the seepage has in fact a large impact on slope stability [1-3], and therefore it is necessary to take certain anti-seepage treatment for the eastern slope via discussions.

According to numerous studies and demonstrations, the cutoff wall is an effective anti-seepage measure [4-5]. This paper focuses on the calculation and analysis of the seepage field of the eastern slope of Yanshan iron ore under different conditions, and provides references and suggestions for anti-seepage projects.

\section{Seepage Calculation and Analysis on Typical Section of Eastern Slope of Yanshan Iron Ore}

The typical slope section No.5 is selected from the eastern slope of Yanshan iron ore for seepage calculation according to the relevant information. The regularities and characteristics of seepage field with or without anti-seepage measures were discussed, and the sensitivity analysis on parameters of anti-seepage measures were achieved to obtain effective parameters of anti-seepage measures for engineering reference. 
According to the geological survey results, the geological structure of the eastern slope section No.5 of Yanshan iron ore is shown in Fig.1:

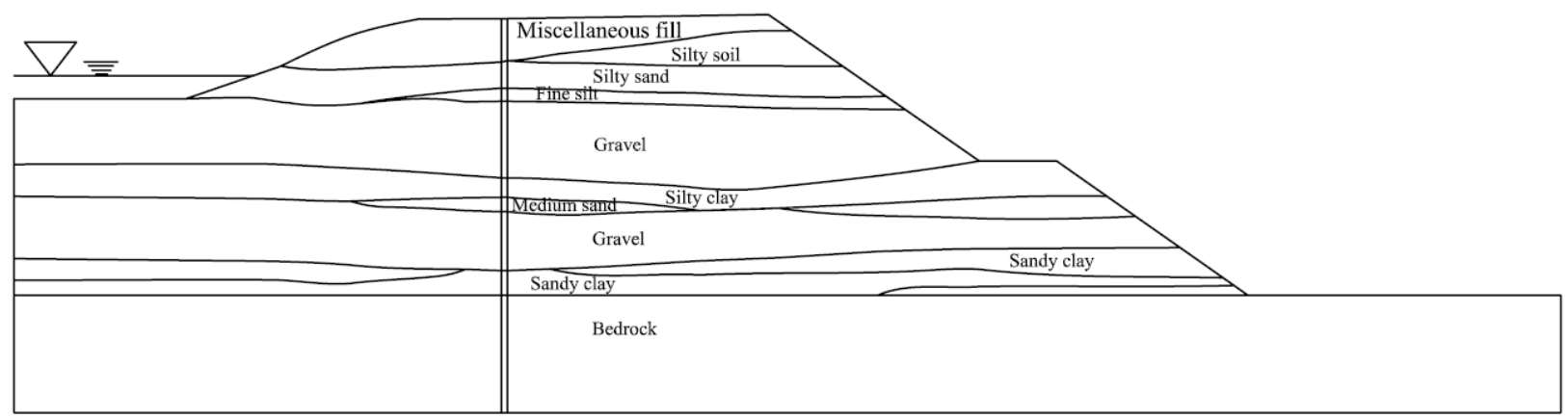

Fig.1 The geological structure diagram of the eastern slope section No.5 of Yanshan

The permeable partition of this section is achieved according to the seepage laboratory finding and the permeability coefficients as shown in Table 1 were used in the calculation:

Table 1 Permeable partition and permeability coefficient of slope section No.5

\begin{tabular}{cccc}
$\begin{array}{c}\text { Permeable } \\
\text { partition }\end{array}$ & $\begin{array}{c}\text { Permeabilit } \\
\text { y coefficient } \\
{[\mathrm{m} / \mathrm{d}]}\end{array}$ & $\begin{array}{c}\text { Permeable } \\
\text { partition }\end{array}$ & $\begin{array}{c}\text { Permeabilit } \\
\text { y coefficient } \\
{[\mathrm{m} / \mathrm{d}]}\end{array}$ \\
\hline Miscellaneous fill & 0.5184 & Silty clay & 0.1728 \\
Silty soil & 0.3456 & Medium sand & 1.728 \\
Silty sand & 0.864 & Sandy clay & 0.2592 \\
Fine silt & 1.296 & Gravel & 4.32 \\
Gravel & 4.32 & Bedrock & 0.2592 \\
\hline
\end{tabular}

In the seepage calculation of section No.5, the known head boundary was applied as the upstream and downstream boundary. According to the relevant hydrological data, the value of upstream head is $43.02 \mathrm{~m}$ and the downstream head $15.7 \mathrm{~m}$. The bottom boundary is impervious and the upstream of slope is water infiltration. Based on field conditions, the anti-seepage measure is mainly the continuous concrete wall. When calculating, a comprehensive survey of anti-seepage effect is achieved by monitoring the upstream and downstream water level of impervious structure and the slope spill point level, as shown in Fig.2.

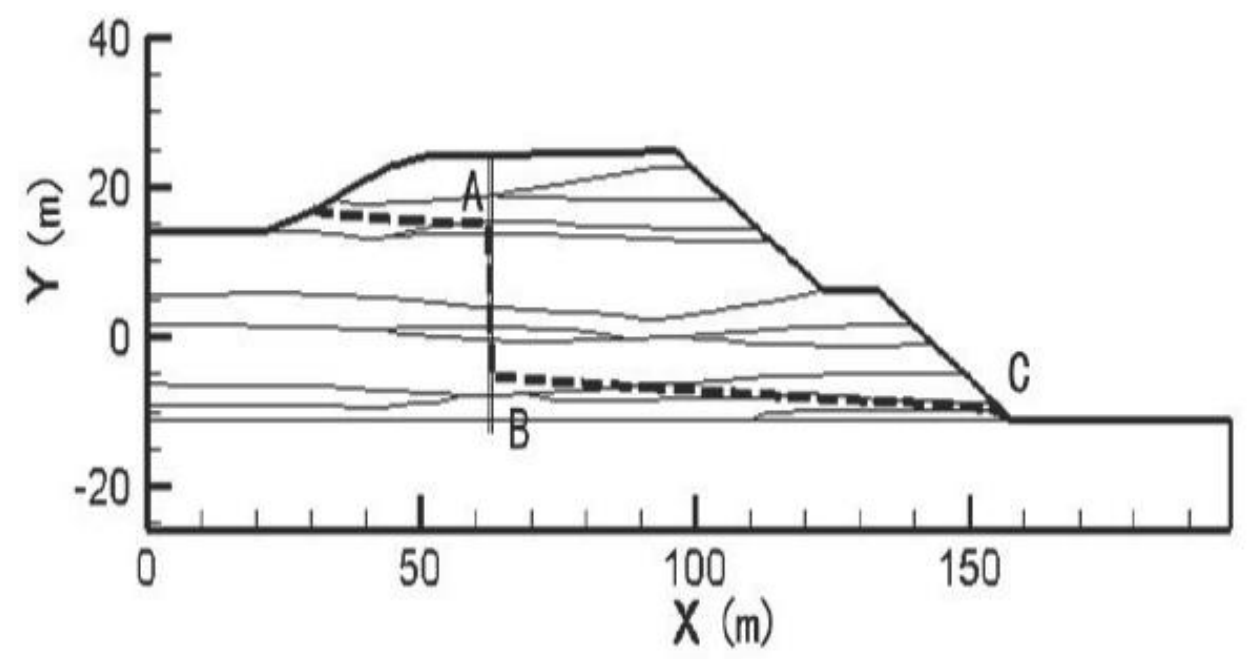

Fig.2 Schematic view of water level monitoring points settings of eastern slope section No.5 of Yanshan

Under the conditions that different permeability parameters are selected for the impervious structure, a changing curve with the variation of every critical water level monitoring point is obtained, as shown in Fig.3- Fig.5. 


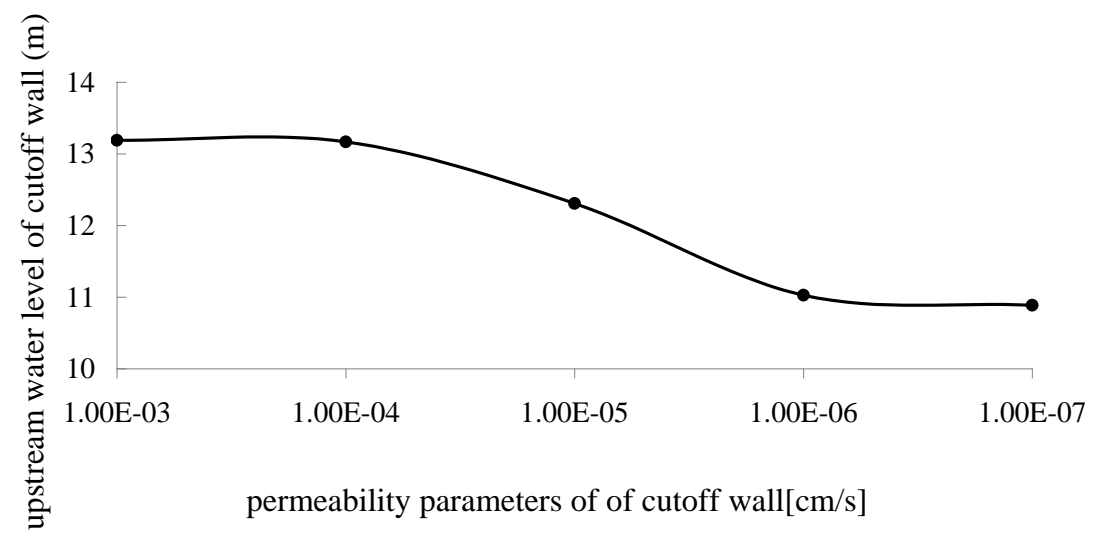

Fig.3 The variation curve of upstream water level of cutoff wall with different permeability parameters

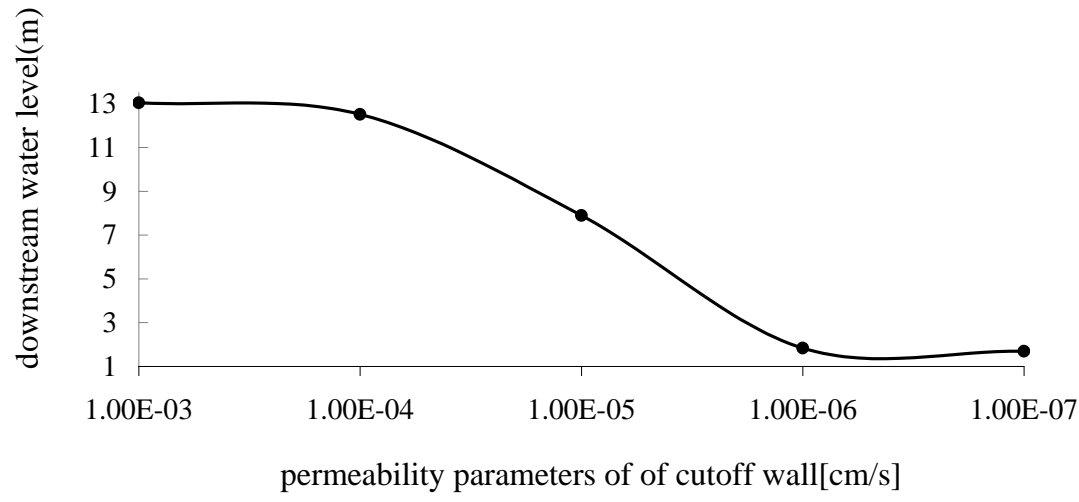

Fig.4 The variation curve of downstream water level with different permeability parameters of cutoff wall

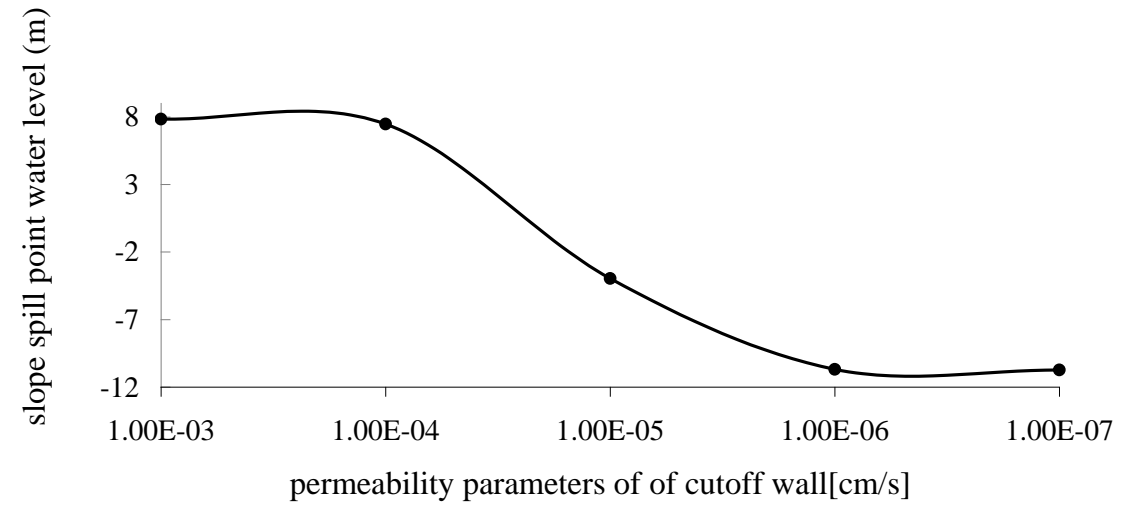

Fig.5 The variation curve of slope spill point water level with different permeability parameters of cutoff wall 
It can be seen from the above sensitivity calculation and analysis of cutoff wall parameters that an inflection point of the curve appeared when the permeability coefficient reached $1 \mathrm{e}-6 \mathrm{~cm} / \mathrm{s}$, and the seepage field was basically and effectively controlled.

The distribution of seepage field without anti-seepage measure when the permeability coefficient reached 1e-6cm/s is shown in Fig.6- Fig.7.

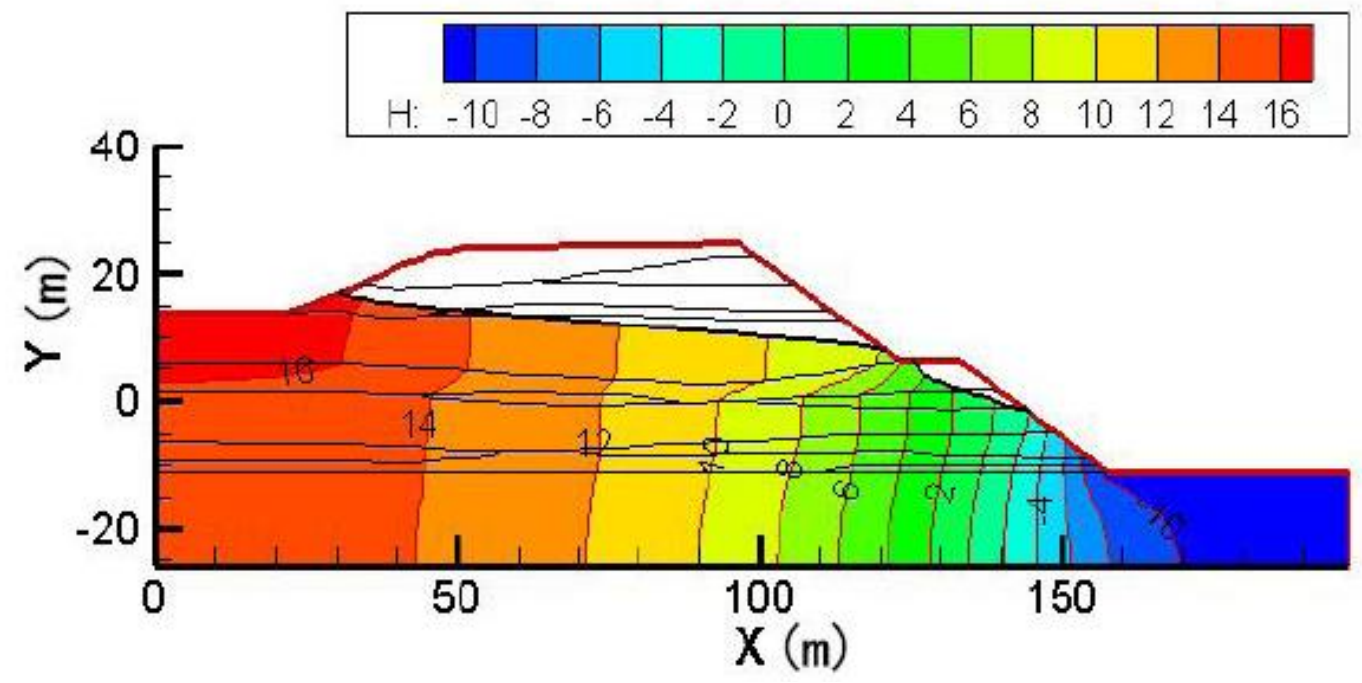

Fig.6 Distribution diagram of seepage field without anti-seepage measure

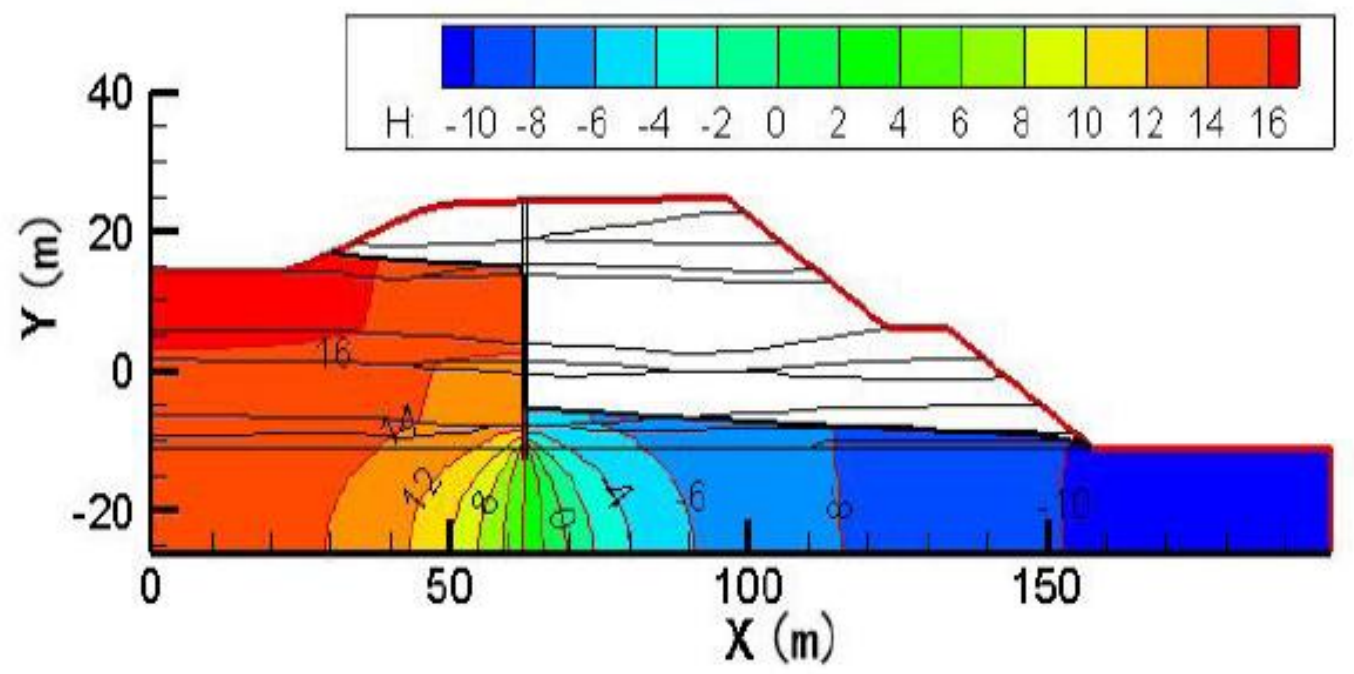

Fig.7 Distribution diagram of seepage field when the permeability coefficient reached $1 \mathrm{e}-6 \mathrm{~cm} / \mathrm{s}$

By comparing with the calculation results of the seepage field without anti-seepage measure when the permeability coefficient reached $1 \mathrm{e}-6 \mathrm{~cm} / \mathrm{s}$, the seepage field was found to have some similar characteristics, for example, the head contour line decreases regularly from upstream to downstream and the equal headline bending appears at stratigraphic boundary. These characteristics are consistent with the actual seepage situation. Without the anti-seepage measure, the positions of saturation line and the slope spill point are relatively high, which cause plenty of seepage and seriously affect the normal production of enterprises. Meanwhile, as most of the rock and soil mass of slope has reached saturation level, the slope failure occurred easily, thus endangering the enterprise equipments and the lives and property of on-site personnel. Under the seepage measure conditions, the downstream water level of cutoff wall as well as the water level of slope spill point decline gradually with the continuous decrease of permeability parameters, which means the cutoff wall can control seepage field and then seepage discharge effectively by reducing observably the height of saturated surface. The calculation results show that when selecting impermeable material and at the time of engineering construction, the permeability coefficient should reach at least $1 \mathrm{e}-6 \mathrm{~cm} / \mathrm{s}$ in order to ensure the anti-seepage effect. 


\section{Conclusion}

The seepage calculation and analysis of the eastern slope section of Yanshan iron ore is achieved in this paper. The results show that without any anti-seepage measure, the slope level is relatively high with a large pit water inflow, so the slope will probably in an unstable state. By setting cutoff wall, the saturation line is effectively declined and the pit water inflow reduced. According to the calculation results, the permeability coefficient should reach at least $1 \mathrm{e}-6 \mathrm{~cm} / \mathrm{s}$ in order to control the seepage field at the time of engineering construction.

\section{Acknowledgements}

This work is supported by the National Natural Science Foundation of China (Grant No. 41201007, 51474048), the Opening fund of State Key Laboratory of Geohazard Prevention and Geoenvironment Protection of Chengdu University of Technology (Grant No. Sklgp2012K010), the Fundamental Research Funds for the Central Universities of China (Grant No. N130401003, L1501009), and the Research Fund for General Science Project of Department of Education of Liaoning Province (Grant No. L2013103).

\section{References}

[1] Xian Wang, Xiaowei Liu and Shuwei Zhang: Modern Mining. Vol. 28(2012),p.69-70.[In Chinese]

[2] Jingren Zhou, Tianhong Yang, Qinglei Yu, Honglei Liu, Fengzhu Li and Shiqing Nan: Metal Mine. Vol.32(2014), p.11-15.[In Chinese]

[3] Zhiguo Wang, Haiming Feng, Lin Liu and Lixin Ai: Industrial Minerals \& Processing. Vol.26(2014), p.31-34.[In Chinese]

[4] Lixin Ai, Wei Lin, Mengjun Xu, Yanhua Wang and Lianjun Guo: Industrial Minerals \& Processing. Vol. 27(2015), p.43-45.[In Chinese]

[5] Shudong Zhang: Metal Mine. Vol. 44(2015), p.139-143.[In Chinese] 